\title{
Coronary Artery Stenosis in Victims of Sudden Death on Medicolegal Autopsy and its Incidence Rate
}

\author{
KHURRAM SALEEM ${ }^{1}$, TASNEEM MURAD ${ }^{2}$, TALHA NAEEM ${ }^{3}$, SHEEBA SHABBIR ${ }^{4}$, SOBIA PARVEEN ${ }^{5}$ \\ ${ }^{1}$ Demonstrator Forensic Medicine Sheikh Zayed Medical College, Rahim Yar Khan \\ ${ }^{2}$ Assistant Professor, Forensic Medicine and Toxicology Department, Islamic International Medical Collage, Rawalpindi \\ ${ }^{3}$ Associate Professor Forensic Medicine, QAMC Bahawalpur \\ ${ }^{4}$ Assistant Professor, Forensic Medicine and Toxicology, HBS Medical and Dental College Islamabad \\ ${ }^{5}$ Associate Professor Forensic Medicine, Abu Umara Medical and Dental College, \\ Corresponding author: Dr Khurram Saleem, Email; Khurram188@yahoo.com, Cell \# +92 3317554529
}

\begin{abstract}
Coronary artery stenosis and the resulting ischemia of the heart is one of the leading causes of death worldwide. Along with worldwide research on the subject, research is being carried out on the subject in the Nishtar Hospital, Multan. Men are most affected. More morbidity occurs in the last decades of life. However, in some cases, the younger age group is also involved. This is also seen on the top page with higher education and urban settlements. Smoking and alcohol are the main risk factors. This often affects entrepreneurs and service owners. Cardiologists and treating physicians, as well as the general public, need lifestyle changes to consider early treatment and avoid unwanted complications.

Aim: This study was conducted to investigate atherosclerotic events in the coronary arteries of sudden death victims.

Methods: Research material consisting of 82 randomly selected cases from a total of 980 autopsies carried out due to sudden death in the period from May 2020 to January 2021 at the Forensic Medicine Department of Sheikh Zayed Hospital, Rahim Yar Khan and Islamic International Medical Collage, Rawalpindi. Information on the date, time and place of death, etc. obtained from the investigating police officer or from accompanying family members. 2. Clear cardiovascular diseases and events and current records were obtained from relatives or family members and accompanying police officers. 3. Sociodemographic data was obtained from relatives of the victim. The autopsy and histopathological findings were recorded. The cause of death was determined and the collected data were subjected to statistical analysis.

Results: The incidence of coronary stenosis was found in 47 out of 82 cases. In this study, the highest number of cases was recorded in the age groups 17 and 14, and 61-70 and 51-60 years, respectively. Men outnumbered 39 cases and females 8 cases. The youngest participant was a 24-year-old man and the oldest was a 78-year-old woman.

Conclusion: The study showed an unexpectedly high incidence of coronary stenosis in this region. Although the incidence is higher in men than in women, it is alarming for both sexes. Cardiologists and treating physicians, as well as the general public, need to change their lifestyle, consider early treatment, avoid unwanted complications, and raise awareness about the disease.

Key words: Coronary artery stenosis, Men, Smoking and Alcohol, Businessmen.
\end{abstract}

\section{INTRODUCTION}

Coronary artery obstruction causing heart ischemia is a very common cause of sudden death ${ }^{1-2}$. The main pathological process is atherosclerosis or atherosclerosis of the coronary arteries. The incidence of ischemic heart disease most often begins in middle age, but the effects of the disease process, including sudden death, are not uncommon in the younger age groups ${ }^{3-4}$. Coronary artery disease is responsible for approximately $70 \%$ of sudden deaths, and $50 \%$ of them have no known clinical symptoms. Coronary atherosclerosis is also sometimes referred to as the "captain of the people of death ${ }^{5-6}$." Cardiologists say at least $80 \%$ of normal lumen must be lost before myocardial necrosis can occur. However, most forensic pathologists blame coronary atherosclerosis for death in which much less lumen function is lost. The global burden of disease survey found 5.2 million deaths from cardiovascular disease in developed countries and 9.1 million deaths in developing countries in 1990. By 2021, there will be an almost $75 \%$ increase in global cardiac burden of vascular disease affecting developing countries ${ }^{7}$ 8 . The incidence of coronary atherosclerosis and cardiovascular events varies widely with age, gender and location. Rapid urbanization, dietary changes, smoking and alcohol abuse, high levels of stress at work, as well as diabetes and high blood pressure are pushing society towards this cardiovascular risk $^{9}$. Despite significant advances in medical and interventional cardiology and emergency care, the incidence of coronary artery disease appears to be high $^{10}$.

The right coronary artery departs from the right aortic sinus, passes the pulmonary trunk and follows the right AV groove without separating any major branches near the origin. A small marginal vein emerges on the right edge of the heart, the main branch runs to the back of the heart where it becomes the posterior descending artery. The left coronary artery departs from the left aortic sinus and radiates through the anterior descending branch from the interventricular septum to the apex and circumferential branch that runs along the left AV groove to reach the posterior part of the heart ${ }^{11}$. The vein arrangement in the back of the heart changes between the left circumflex artery and the right coronary artery. Common sites of stenosis with or without thrombosis are the first part of the 
anterior descending branch of the left coronary artery within $2 \mathrm{~cm}$ from the origin, then the proximal part of the right coronary artery, the first part of the circumscribing coronary artery. the left coronary artery and the short main trunk of the left coronary artery ${ }^{12}$. This study was conducted to investigate atherosclerotic events in the coronary arteries of sudden death victims.

\section{METHODS}

Research material consisting of 82 randomly selected cases from a total of 980 autopsies carried out due to sudden death in the period from May 2020 to January 2021 at the Forensic Medicine Department of Sheikh Zayed Hospital, Rahim Yar Khan and Islamic International Medical Collage, Rawalpindi.

\section{Selection Criteria}

Inclusion criteria: 82 randomly selected sudden deaths.

Exclusion Criteria: Broken or decomposed bodies are excluded.

1. Information on the date, time and place of death, etc. obtained from the investigating police officer or from accompanying family members. 2. Clear cardiovascular diseases and events and current records were obtained from relatives or family members and accompanying police officers. 3. Sociodemographic data was obtained from relatives of the victim.

\section{Autopsy Examination}

A. External body examination and related findings are recorded.

B. Internal control

1. The skull, thorax and abdominal cavity were opened according to the routine post-mortem examination.

2. The heart is examined for discoloration, enlargement, or adhesions, including the pericardial space, for blood or other fluids. Heart weight obtained.

\section{Histopathology}

A $10 \%$ formalin solution was used to protect the heart. The coronary arteries were sectionedtransversely at intervals of 2 to $3 \mathrm{~mm}$ along their course. Sections for further processing were taken as follows: Rt $(A)-2 \mathrm{~cm}$ proximal to the ostium of the right coronary artery $\mathrm{Rt}(\mathrm{B})-2 \mathrm{~cm}$ behind the exit to the right lateral border of the heart. Rt $(C)$ Posterior descending artery Lt $(A)$ - Left main trunk Lt $(B)$ Left anterior descending artery Lt $(C)$ - Left circumferential artery 1 . The heart is open in the direction of blood flow, thickness of the walls of the ventricle, damage valves, etc. However, the intensity of lumenpatency was not observed in the study. 2. The cause of death was determined and the collected data were subjected to statistical analysis.

\section{RESULTS}

The incidence of coronary stenosis was found in 47 out of 82 cases. In this study, the highest number of cases was recorded in the age groups 17 and 14, and 61-70 and 5160 years, respectively. Men outnumbered 39 cases and females 8 cases. The youngest participant was a 24 -yearold man and the oldest was a 78-year-old woman. The most involved group was 61-70 men and 51-60 women. The table below shows the results.

\begin{tabular}{|l|l|l|l|l|}
\hline Age group & Male & Female & Total & $\begin{array}{l}\text { Percentage of cases } \\
\text { involved }\end{array}$ \\
\hline $0-10$ & 0 & 0 & 0 & 0 \\
\hline $11-20$ & 0 & 0 & 0 & 0 \\
\hline $21-30$ & 2 & 0 & 2 & 4.23 \\
\hline $31-40$ & 5 & 1 & 6 & 12.77 \\
\hline $41-50$ & 6 & 1 & 7 & 14.90 \\
\hline $51-60$ & 7 & 2 & 9 & 19.14 \\
\hline $61-70$ & 12 & 1 & 13 & 27.66 \\
\hline 71 and above & 7 & 3 & 10 & 21.23 \\
\hline Total & 39 & 8 & 47 & 82 \\
\hline
\end{tabular}

As shown in the figure below, most of the cases have occurred in urban areas.

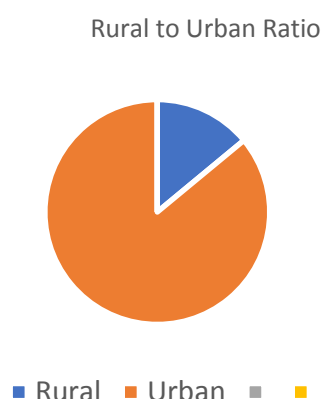

Fig. 1: Urban and rural distribution of cases

Most of the cases of coronary artery stenosis were in the educated class who enrolled above graduation level. There have been very few illiterate or unrecorded cases.

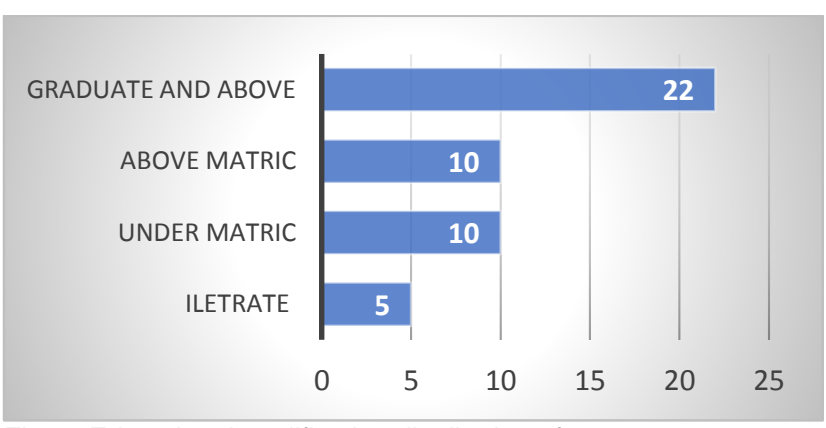

Fig. 2: Educational qualification distribution of cases

Most of the caseswere related to tobacco use or smoking and alcohol, or both.

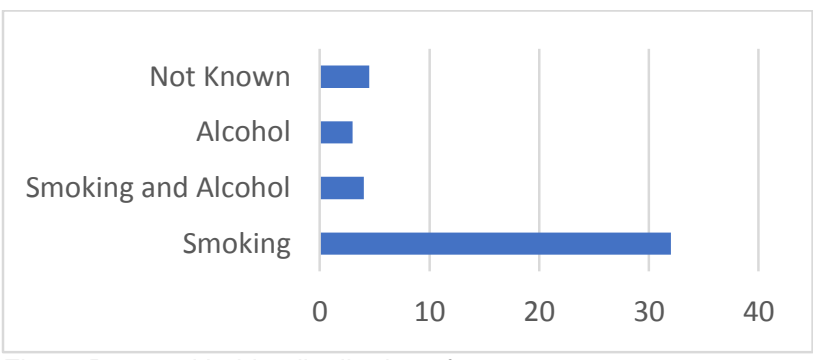

Fig. 3: Personal habits distribution of cases 
The study shows that the business manis most affected by coronary artery stenosis ( 21 cases), followed by those in service with 9 cases. An interesting fact is the participation of 3 young students.

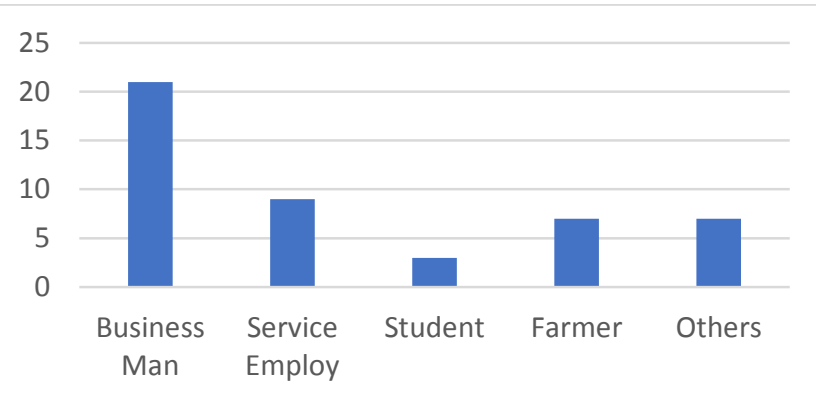

Fig. 4: Occupational distribution of cases

\section{DISCUSSION}

In this study, $57.3 \%$ of the 82 cases showed coronary stenosis. This is almost comparable with the observations of employees such as Wig KL et al. (64\%), Subramaniam R et al. (62\%) and Singh V et al. (68\%) $)^{13-14}$. However, Garg M et al. (46.4\%) reported a lower incidence in their study. The study is similar to the results of the studies by Garga $M$ et al. And Dhruba GA et al., Who reported a higher incidence in the sixth and seventh decades of life. The higher incidence in males compared to females is consistent with all previous studies on the incidence of coronary stenosis. This can be attributed to men who are more exposed to stress and more prone to the effects of smoking and alcohol $^{15-16}$. The higher incidence in the urban population is consistent with the findings of Konishi $\mathrm{M}$ et al., Who found a growing trend of myocardial infarction in the urban population. This is mainly due to a sedentary lifestyle and changed eating habits, as well as changes in the lifestyle of city dwellers ${ }^{17-18}$. The tendency to become more skilled with the disease more frequent is in line with the findings of Sarvotham SG and Berry JN. However, Gupta R et al found that illiteracy and lower education were associated with greater exposure to risk factors leading to increased morbidity ${ }^{19-20}$. This difference may be due to the fact that low educated people generally do not report sudden deaths to justify a forensic autopsy in the workplace. Regarding the occupation, it can be seen that hired or servant workers are the most affected ${ }^{21-22}$. This is in contrast to the findings of Gupta R et al. Who found a higher incidence in the lowemployment population? The fact that the studied area is a city may result from the greater exposure of the population to risk factors ${ }^{23}$. Personal habits are more common in a population with active tobacco and alcohol consumption, which is consistent with most studies.

\section{CONCLUSION}

The study showed an unexpectedly high incidence of coronary stenosis in this region. Although the incidence is higher in men than in women, it is alarming for both sexes. Age has a predominant influence. This study highlights the importance of screening for cardiovascular risk factors from the beginning of the third decade of life. Smoking and alcoholism can accelerate the development of coronary stenosis. All observations in this study indicated that the incidence of coronary stenosis is alarming. Cardiologists and treating physicians, as well as the general public, need to change their lifestyle, consider early treatment, avoid unwanted complications, and raise awareness about the disease.

\section{REFERENCES}

1. Vähätalo J, Holmström L, Pakanen L, Kaikkonen K, Perkiömäki J, Huikuri H, Junttila J. Coronary artery disease as the cause of sudden cardiac death among victims $<50$ years of age. The American Journal of Cardiology. 2021 May 15;147:33-8.

2. Kauppila JP, Pakanen L, Porvari K, Vähätalo J, Holmström L, Perkiömäki JS, Huikuri HV, Junttila MJ. Blood alcohol levels in Finnish victims of non-ischaemic sudden cardiac death. Annals of Medicine. 2021 Jan 1;53(1):413-9.

3. Rahman AA, Raveendran R. Proportion of Diagonal Ear Lobe Crease and its Association With Sudden Death Due to Coronary Artery Disease-An Autopsy Study. Indian Journal of Forensic Medicine \& Toxicology. 2020 Jul 1;14(3).

4. Jomaa SB, Salem NH, Hmila I, Saadi S, Aissaoui A, Belhadj M, Chadly A. Sudden death and hydatid cyst: A medicolegal study. Legal Medicine. 2019 Sep 1;40:17-21.

5. Holmström L, Haukilahti A, Vähätalo J, Kenttä T, Appel H, Kiviniemi A, Pakanen L, Huikuri HV, Myerburg RJ, Junttila J. Electrocardiographic associations with myocardial fibrosis among sudden cardiac death victims. Heart. 2020 Jul 1;106(13):1001-6.

6. Sessa F, Esposito M, Messina G, Di Mizio G, Di Nunno N, Salerno M. Sudden Death in Adults: A Practical Flow Chart for Pathologist Guidance. InHealthcare $2021 \mathrm{Jul}$ (Vol. 9, No. 7, p. 870). Multidisciplinary Digital Publishing Institute.

7. Rana NM, Pandey AR. A Profile Study of Sudden Natural Death Cases in Vadodara Region of Central Gujarat. Indian Journal of Forensic Medicine \& Toxicology. 2020 Jul 1;14(3).

8. Holmström L, Pylkäs K, Tervasmäki A, Vähätalo J, Porvari K, Pakanen L, Kaikkonen KS, Perkiömäki JS, Kiviniemi AM, Kerkelä R, Ukkola O. Genetic contributions to the expression of acquired causes of cardiac hypertrophy in non-ischemic sudden cardiac death victims. Scientific reports. 2021 May 27;11(1):1-8.

9. Ekström K, Lehtonen J, Nordenswan HK, Mäyränpää MI, Räisänen-Sokolowski $A$, Kandolin $R$, Simonen $P$, PietiläEffati $P$, Alatalo A, Utriainen S, Rissanen TT. Sudden death in cardiac sarcoidosis: an analysis of nationwide clinical and cause-of-death registries. European heart journal. 2019 Oct $1 ; 40(37): 3121-8$.

10. Vähätalo JH, Huikuri HV, Holmström LT, Kenttä TV, Haukilahti MA, Pakanen L, Kaikkonen KS, Tikkanen J, Perkiömäki JS, Myerburg RJ, Junttila MJ. Association of silent myocardial infarction and sudden cardiac death. JAMA cardiology. 2019 Aug 1;4(8):796-802.

11. Hietanen S, Herajärvi J, Junttila J, Pakanen L, Huikuri HV, Liisanantti J. Characteristics of subjects with alcoholic cardiomyopathy and sudden cardiac death. Heart. 2020 May 1;106(9):686-90.

12. Lynge TH, Svane J, Pedersen-Bjergaard U, Gislason G, Torp-Pedersen C, Banner J, Risgaard B, Winkel BG, TfeltHansen J. Sudden cardiac death among persons with diabetes aged 1-49 years: a 10-year nationwide study of 14 294 deaths in Denmark. European heart journal. 2020 Jul 21;41(28):2699-706.

13. Narsireddy R. An autopsy study of sudden natural deaths conducted at Govt hospital.

14. Michaud K, Magnin V, Faouzi M, Fracasso T, Aguiar D, Dedouit F, Grabherr S. Postmortem coronary artery calcium score in cases of myocardial infarction. International journal of legal medicine. 2021 Apr 13:1-8. 
15. Lynge TH, Nielsen TS, Winkel BG, Tfelt-Hansen J, Banner J. Sudden cardiac death caused by myocarditis in persons aged 1-49 years: a nationwide study of 14294 deaths in Denmark. Forensic sciences research. 2019 Jul 3;4(3):24756.

16. Lynge TH, Nielsen TS, Winkel BG, Tfelt-Hansen J, Banner J. Sudden cardiac death caused by myocarditis in persons aged 1-49 years: a nationwide study of 14294 deaths in Denmark. Forensic sciences research. 2019 Jul 3;4(3):24756.

17. Malik Khan MR, Rao BS. A Study of Autopsy Findings in Cases of Sudden Cardiac Death at Kakatiya Medical College and Hospital Warangal. Indian Journal of Forensic Medicine \& Toxicology. 2020 Oct 1;14(4).

18. Tan HL, van Dongen LH, Smits RL, van Valkengoed IG. Can we better understand sudden cardiac death by including data from unwitnessed victims?.Europace. 2021 Jun;23(6):819.

19. Kaur M, Rahimi R, Razali F, Noor NM, Omar E, Manaf ZA, Mahmood MS, Abdullah N, Nawawi H. Association of coronary artery calcium score with calcification and degree of stenosis: An autopsy study. The Malaysian journal of pathology. 2019 Aug 1;41(2):177-83.

20. Sabatasso S, Banz $Y$, Ringger R, Visonà $S$, Schyma $C$, Bolliger S, Michaud K. Second opinion system for sudden cardiac death cases in forensic practice. International journal of legal medicine. 2020 May;134(3):1255-63.

21. Paratz ED, Costello B, Rowsell L, Morgan N, Smith K, Thompson T, Semsarian C, Pflaumer A, James P, Stub D, La Gerche A. Can post-mortem coronary artery calcium scores aid diagnosis in young sudden death?. Forensic Science, Medicine and Pathology. 2021 Mar;17(1):27-35.

22. Sharma $V$. To assess sudden deaths due to atherosclerosis in adult population: An autopsy study.

23. Ripoll T, García AB, Gomila I, Heine D, Poncela JL, Sánchez N, Pérez C, García E, Hernández E, Barceló A, Busardo FP. Post-mortem toxicology in the diagnosis of sudden death in young and middle-aged victims. Eur Rev Med Pharmacol Sci. 2019 Nov 1;23(21):9135-49. 